\title{
Epidemiological, Clinical and Serological Characteristics of Children with Coronavirus Disease 2019 in Wuhan: A Single-centered, Retrospective Study
}

\author{
Dan Luo ${ }^{1,2} \cdot$ Zhi Xia $^{3} \cdot$ Heng $\mathrm{Li}^{3} \cdot$ Danna Tu${ }^{3} \cdot$ Ting Wang $^{1} \cdot$ Wei Zhang ${ }^{1} \cdot$ Lu Peng $^{1} \cdot$ Wenfu Yi $^{1} \cdot$ \\ Sai Zhang ${ }^{1} \cdot$ Junhua Shu ${ }^{3} \cdot \mathrm{Hui} \mathrm{Xu}^{3} \cdot \mathrm{Yong}^{3} \mathrm{i}^{3} \cdot{\text { Buyun } \mathrm{Shi}^{3} \cdot \mathrm{Ch}^{3} \text { genjiao Huang }}^{3} \cdot$ Wen Tang $^{3}$. \\ Shuna Xiao ${ }^{3} \cdot$ Xiaolan Shu $^{3} \cdot$ Yan $\mathrm{Liu}^{1} \cdot$ Yuan Zhang ${ }^{1} \cdot$ Shan $\mathrm{Guo}^{2} \cdot \mathrm{Zhi} \mathrm{Yu}^{2} \cdot$ Baoxiang Wang $^{2}$.

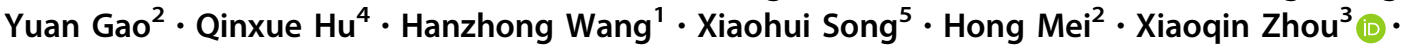 \\ Zhenhua Zheng ${ }^{1}$
}

Received: 26 August 2020 / Accepted: 30 November 2020/Published online: 22 December 2020

(c) Wuhan Institute of Virology, CAS 2020

Dear Editor,

In December 2019, SARS-CoV-2 was first detected in the samples obtained from three adult patients who suffered from an unknown viral pneumonia in Wuhan $(\mathrm{Li}$ et al. 2020). This unknown viral pneumonia is further named as coronavirus disease 2019 (COVID-19) by the World Health Organization. To date, the number of new COVID-19 cases has continued to skyrocket and the impact of SARS-CoV-2 on humans is far greater than any pathogen of this century in both breadth and depth. Previous studies have shown that adults with COVID-19 have symptoms of fever, dry cough, dyspnea, fatigue and lymphocytopenia. Moreover, COVID-19 is more likely to cause death in the elderly, especially those with chronic comorbidities (Huang et al. 2020). In Wuhan, more than 50,000 COVID-19 cases have been confirmed, including

Dan Luo and Zhi Xia have contributed equally to this work.

Electronic supplementary material The online version of this article (https://doi.org/10.1007/s12250-020-00333-z) contains supplementary material, which is available to authorized users.

Zhenhua Zheng

zhengzh@wh.iov.cn

$\triangle$ Xiaoqin Zhou

62724838@163.com

1 CAS Key Laboratory of Special Pathogens and Biosafety, Center for Emerging Infectious Diseases, Wuhan Institute of Virology, Chinese Academy of Sciences, Wuhan 430071, China

2 Department of Gastroenterology, Wuhan Children's Hospital, Tongji Medical College, Huazhong University of Science and Technology, Wuhan 430015, China over 780 pediatric patients, and only one child death case (Lu et al. 2020). Although the number of children cases was far fewer than that of adults, COVID-19 might endanger children's health and the information on children remains limited, especially in serological study. In the retrospective study, the investigators analyzed the epidemiological, clinical and serological characteristics of children with COVID-19 in Wuhan in the early stages of the outbreak, which might provide theoretical and practical help in controlling COVID-19 and similar emerging infectious diseases in the future.

The retrospective study was conducted at Women and Children's Hospital of Hubei Province (Wuhan, China), a designated hospital providing medical services to children with confirmed and suspected COVID-19 during the outbreak. Initially, we enrolled 56 suspected inpatients with COVID-19 from 25 January 2020 to 2 March 2020. Fourteen inpatients with viral pneumonia were positive for SARS-CoV-2 nucleic acid test (named group NP) and diagnosed as confirmed cases with COVID-19. Another 20 suspected inpatients with negative SARS-CoV-2 nucleic acid result were detected by in-house anti-SARS-related

3 Department of Pediatrics, Women and Children's Hospital of Hubei Province, Tongji Medical College, Huazhong University of Science and Technology, Wuhan 430070, China

4 State Key Laboratory of Virology, Wuhan Institute of Virology, Chinese Academy of Sciences, Wuhan 430071, China

5 Department of Obstetrics, Wuhan Maternal and Child Healthcare Hospital, Tongji Medical College, Huazhong University of Science and Technology, Wuhan 430015, China 
A

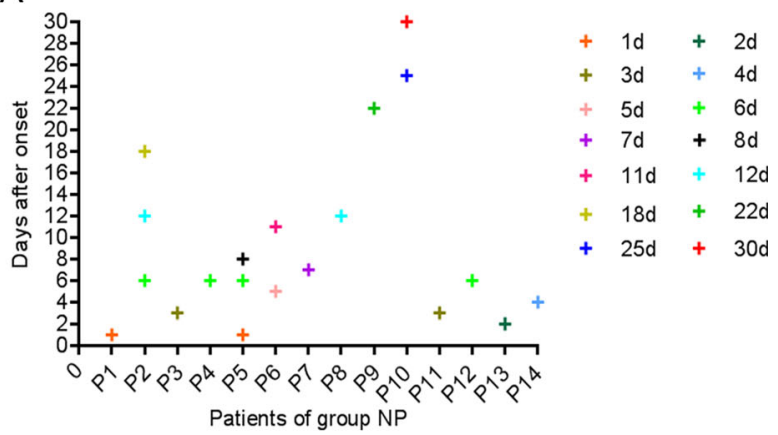

B

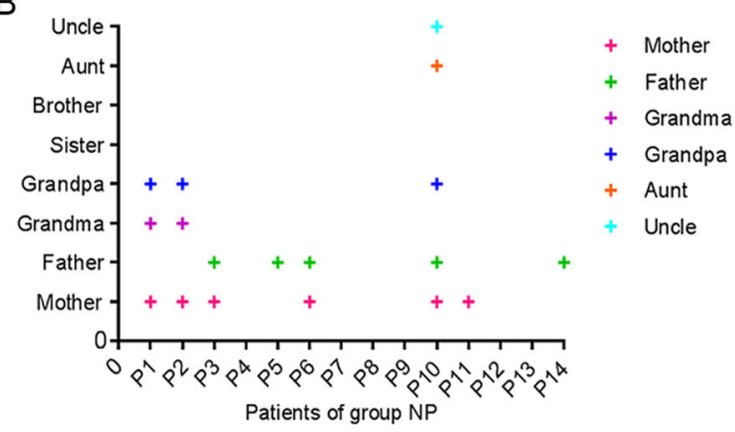

C

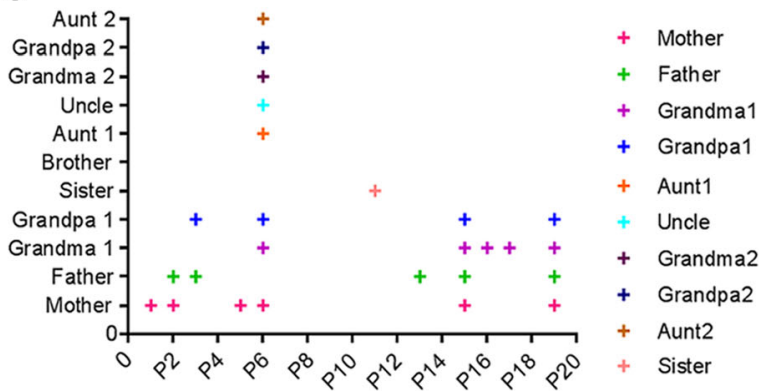

Fig. 1 SARS-CoV-2 nucleic acid test in group NP and familial cluster infection in group NP and AP. A Fourteen patients in group NP were positive for SARS-CoV-2 nucleic acid. B Eight patients in group NP had a contact history, such as parents, grandparents or relatives who were positive for SARS-CoV-2 nucleic acid. C Eleven patients in group AP had a contact history, such as parents, grandparents, sister or relatives who were positive for SARS-CoV-2 nucleic acid.

coronaviruses IgM and IgG ELISA kits in Wuhan Institute of Virology and positive for the antibody (named group AP) (Supplementary Fig. S1). The ELISA kits had been deployed to detect $\operatorname{IgM}$ and $\operatorname{IgG}$ in adult patients with COVID-19 in Wuhan during the outbreak and worked well (Zhang et al. 2020; Zhou et al. 2020). It was the first time of the ELISA kits to be used to detect SARS-CoV-2 antibody in children.

In group NP, most patients were tested positive for viral nucleic acid within 12 days after onset, a small number of patients still tested positive from 18 to 30 days after onset (Fig. 1A). It is suggested that viral shedding of SARSCoV-2 may persist for a long time. In addition, 6 of the 14 patients in group NP were also positive for the antibody (Table 1).

In group NP and AP, the main age distribution were within $0-2$ years old and 6-10 years old, and $10(71.4 \%)$ and $14(70 \%)$ patients were male (Table 2). It suggested that strengthening the protective isolation of infants, toddlers and school-aged children was very important. Compared to girls, boys were more frequently affected. The same dominance of male patients was also observed in adult patients with COVID-19, SARS and MERS (Badawi and Ryoo 2016; Channappanavar et al. 2017; Chen G et al. 2020; Chen N et al. 2020; Huang et al. 2020). The increase in male susceptibility to coronavirus infections could be correlated to Y chromosome and sex hormones, which may be involved in innate and adaptive immunity (Guo et al. 2019; Chen G et al. 2020; Chen N et al. 2020).

In group NP and AP, the 8 and 11 patients caught SARS-CoV-2 through their parents, grandparents, sister or relatives with SARS-CoV-2 nucleic acid positive, respectively (Fig. 1A and 1C). It suggested that children with COVID-19 mainly occurred in familial cluster, when compared to adults with COVID-19, who acquired infection mainly through communities, families, or hospitals (Chan et al. 2020; Chen G et al. 2020; Chen N et al. 2020; Cui et al. 2020; Huang et al. 2020; Su et al. 2020; Wang D et al. 2020; Wang XF et al. 2020). In both groups, 6 out of 8 (75\%) infants were breastfed (Table 2). Since we did not concurrently perform SARS-CoV-2 nucleic acid in breast milk, it was not clear whether the infants get infected by breastfeeding and (or) respiratory transmission of their mothers.
Table 1 SARS-CoV-2 nucleic acid and antibody detection of 34 patients.

\begin{tabular}{llll}
\hline Characteristic & Total $(n=34)$ & Group NP $(n=14)$ & Group AP $(n=20)$ \\
\hline SARS-CoV-2 RNA, No (\%) & $14(41.2)$ & $14 / 14(100.0)^{*}$ & $0 *$ \\
SARS-CoV-2 antibody, No $(\%)$ & & & \\
Ig M (+) and / or IgG (+) & $26(100.0)$ & $6 / 6(100.0)$ & $20(100.0)$ \\
Only Ig M (+) & $3(11.5)$ & $1 / 6(16.7)$ & $2(10.0)$ \\
Only IgG (+) & $16(61.5)$ & $3 / 6(50.0)^{*}$ & $13(65.0)^{*}$ \\
IgM (+) and Ig G (+) & $7(26.9)$ & $2 / 6(33.3)$ & $5(25.0)$ \\
\hline
\end{tabular}

*Refers to a statistically significant difference between group NP and group AP, $P<0.05$. 
Table 2 Epidemiological and clinical characteristics of 34 patients.

\begin{tabular}{|c|c|c|c|}
\hline Characteristic & Total $(n=34)$ & Group NP $(n=14)$ & Group AP $(n=20)$ \\
\hline Age, y, median (IQR) & $5.0(1.0-9.0)$ & $5.6(1.1-9.0)$ & $4.5(0.9-9.4)$ \\
\hline \multicolumn{4}{|l|}{ Age distribution, No. (\%) } \\
\hline $0-1$ years & $8(23.5)$ & $3(21.5)$ & $5(25.0)$ \\
\hline $1-2$ year & $8(23.5)$ & $2(14.3)$ & $6(30.0)$ \\
\hline $2-6$ years & $3(8.8)$ & $1(7.1)$ & $2(10.0)$ \\
\hline $6-10$ years & $10(29.4)$ & $7(50.0)$ & $3(15.0)$ \\
\hline$>10$ years & $5(14.7)$ & $1(7.1)$ & $4(20.0)$ \\
\hline \multicolumn{4}{|l|}{ Gender, No. (\%) } \\
\hline Female & $10(29.4)$ & $4(28.6)$ & $6(30.0)$ \\
\hline Male & $24(70.6)$ & $10(71.4)$ & $14(70.0)$ \\
\hline Familial cluster, No. (\%) & $19(55.9)$ & $8(57.1)$ & $11(55.0)$ \\
\hline Breast feeding, No. $(\%)(<1 \mathrm{y}) \mathscr{H}$ & $6 / 8(75.0)$ & 3/3 (100.0) & $3 / 5(60.0)$ \\
\hline Coexisting disorder, No. (\%) & $1(2.9)$ & 0 & $1(5.0)$ \\
\hline \multicolumn{4}{|l|}{ Clinical classification } \\
\hline Common & $30(88.2)$ & $13(92.9)$ & $17(85.0)$ \\
\hline Severe & $4(11.8)$ & $1(7.1)$ & $3(15.0)$ \\
\hline Time from illness onset to hospital, ds, median (IQR) & $15.8(9.0-19.3)$ & $18.4(9.8-24.3)$ & $14.0(9.0-16.3)$ \\
\hline \multicolumn{4}{|l|}{ Symptoms and signs, No. (\%) } \\
\hline Fever & $24(70.6)$ & $10(71.4)$ & $14(70.0)$ \\
\hline Cough & $28(82.4)$ & $13(92.6)$ & $15(75.0)$ \\
\hline Sputum production & $15(44.1)$ & $6(42.9)$ & $9(45.0)$ \\
\hline Shortness of breath & $4(11.8)$ & $1(7.1)$ & $3(15.0)$ \\
\hline Cyanosis & $1(2.9)$ & $1(7.1)$ & 0 \\
\hline Sore throat & $3(8.8)$ & $1(7.1)$ & $2(10.0)$ \\
\hline Running nose & $8(23.5)$ & $4(28.6)$ & $4(20.0)$ \\
\hline Vomiting & $4(11.8)$ & 0 & $4(15.0)$ \\
\hline Diarrhea & $2(5.9)$ & $1(7.1)$ & $1(5.0)$ \\
\hline \multicolumn{4}{|l|}{ Blood routine, $\left(\right.$ normal; $\left.\times 10^{9} / \mathrm{L}\right)$, median $(\mathrm{IQR})$} \\
\hline Leukocyte count, (5.5-12.0) & $8.2(6.1-9.7)$ & $6.1(4.9-7.7)^{*}$ & $9.7(6.7-11.5)^{*}$ \\
\hline Neutrophil count, (1.1-3.9) & $4.5(2.1-5.5)$ & $2.9(1.4-4.4)^{*}$ & $5.6(3.1-7.8)^{*}$ \\
\hline Lymphocyte count, (1.2-6.0) & $3.0(1.5-4.2)$ & $2.5(1.4-3.1)$ & $3.3(1.8-4.6)$ \\
\hline$<1.2$, No. $(\%)$ & $4(11.8)$ & $1(7.1)$ & $3(15.0)$ \\
\hline $1.2-6.0$, No. $(\%)$ & $26(76.5)$ & $12(85.7)$ & $14(70.0)$ \\
\hline$>6.0$, No. $(\%)$ & $4(11.8)$ & $1(7.1)$ & $3(15.0)$ \\
\hline Platelet count, (100-300) & $255(158-325)$ & $252(144-300)$ & $257(165-333)$ \\
\hline \multicolumn{4}{|l|}{ Infection-related biomarkers (normal range), median (IQR) } \\
\hline C-reactive protein, $(0-10.0 \mathrm{mg} / \mathrm{L})$ & $9.4(0.3-11.6)$ & $3.7(0-8.5)$ & $13.5(2.0-15.4)$ \\
\hline$>10$, No. $(\%)$ & $9(26.5)$ & $3(21.4)$ & $6(30.0)$ \\
\hline Procalcitonin, $(<0.05 \mathrm{ng} / \mathrm{mL})^{\mathrm{a}}$ & $0.7(0.1-0.9)$ & 0.1 & $0.8(0.1-0.9)$ \\
\hline$>0.05$, No. $(\%)$ & $11(78.6)$ & $1 / 1(100.0)$ & $10 / 13(76.9)$ \\
\hline \multicolumn{4}{|l|}{ Humoral immunity, (normal; g/L), median $(\mathrm{IQR})^{\mathrm{b}}$} \\
\hline $\operatorname{IgA},(0.14-2.7)$ & $1.0(0.2-1.3)$ & $1.3(0.27-2.2)$ & $0.7(0.17-1.24)$ \\
\hline $\operatorname{IgM},(0.15-2.6)$ & $1.0(0.6-1.3)$ & $1.0(0.5-1.6)$ & $0.9(0.7-1.3)$ \\
\hline $\operatorname{IgG},(3.0-16.5)$ & $7.8(6.4-10.9)$ & $8.1(5.2-11.6)$ & $7.6(6.5-10.5)$ \\
\hline \multicolumn{4}{|l|}{ Liver and kidney function, (normal range), median (IQR) } \\
\hline ALT, (5-40 U/L) & $23.0(13.4-27.3)$ & $22.8(12.4-28.4)$ & $23.0(14.9-27.5)$ \\
\hline AST, (8-40 U/L) & $35.5(25.6-43.0)$ & $35.1(25.0-44.1)$ & $35.8(26.1-43.7)$ \\
\hline $\mathrm{TB},(1.71-17.1 \mu \mathrm{mol} / \mathrm{L})$ & $6.1(3.4-7.9)$ & $5.8(3.5-7.1)$ & $6.3(3.2-9.1)$ \\
\hline
\end{tabular}


Table 2 (continued)

\begin{tabular}{|c|c|c|c|}
\hline Characteristic & Total $(n=34)$ & Group NP $(n=14)$ & Group AP $(n=20)$ \\
\hline BUN, (2.9-7.1 mmol/L) & $3.7(2.9-4.5)$ & $3.6(3.1-4.6)$ & $3.7(2.8-4.5)$ \\
\hline CRE, $(30-106 \mu \mathrm{mol} / \mathrm{L})$ & $32.0(22.0-42.0)$ & $35.25(24.1-47.8)$ & $30.4(22.0-36.5)$ \\
\hline \multicolumn{4}{|l|}{ Co-infection, No. (\%) } \\
\hline Mycoplasma- $\operatorname{IgG}(\geq 1: 160)$ & $14(41.2)$ & $5(35.7)$ & $9(45.0)$ \\
\hline Influenza virus A-RNA (+) & $1(2.9)$ & 0 & $1(5.0)$ \\
\hline Respiratory syncytial virus-RNA (+) & $6(17.6)$ & $4(28.6)$ & $2(10.0)$ \\
\hline Epstein-Barr virus-DNA (+) & $1(2.9)$ & $1(7.1)$ & 0 \\
\hline Sputum culture for streptococcus pneumonia & $1(2.9)$ & $1(7.1)$ & 0 \\
\hline \multicolumn{4}{|l|}{ Computed tomography, No. (\%) } \\
\hline Ground-glass opacity & $14(41.2)$ & $6(42.8)$ & $8(40.0)$ \\
\hline Local patchy shadowing & $25(73.5)$ & $10(71.4)$ & $15(75.0)$ \\
\hline Bilateral patchy shadowing & $16(47.1)$ & $6(42.8)$ & $10(50.0)$ \\
\hline Right lung patchy shadowing & $24(70.6)$ & $11(78.6)$ & $13(65.0)$ \\
\hline \multicolumn{4}{|l|}{ Treatment, No. (\%) } \\
\hline Antiviral therapy & $24(70.6)$ & $13(92.9)^{*}$ & $11(55.0)^{*}$ \\
\hline Antibiotic therapy & $34(100.0)$ & $14(100.0)$ & $20(100.0)$ \\
\hline Immunoglobin & $1(2.9)$ & 0 & $1(5.0)$ \\
\hline Corticosteroid & $2(5.8)$ & $1(7.1)$ & $1(5.0)$ \\
\hline Chinese patent drug & $16(47.1)$ & $9(64.3)$ & $7(35.0)$ \\
\hline Oxygen support & $4(11.8)$ & $1(7.1)$ & $3(15.0)$ \\
\hline \multicolumn{4}{|l|}{ Prognosis, No. (\%) } \\
\hline Discharge & $34(100.0)$ & $14(100.0)$ & $20(100.0)$ \\
\hline Hospital stays, ds, median (IQR) & $9.4(7.0-12.0)$ & $11.2(6.8-16.3)$ & $8.2(7.0-8.8)$ \\
\hline
\end{tabular}

Group NP, confirmed cases with SARS-CoV-2 nucleic acid positive. Group AP, cases with SARS-CoV-2 antibody positive. IQR, interquartile range; Ig, immunoglobulin; ALT, alanine aminotransferase; AST, aspartate aminotransferase;TB, total bilirubin;BUN, blood urea nitrogen; CRE, creatinine; RNA, ribonucleic Acid; DNA, deoxyribonucleic acid; +, positive.

HEight infants were included in the study, in which six infants were breastfed and two infants were formula fed.

*Refers to a statistically significant difference between group NP and group AP, $P<0.05$.

${ }^{a}$ Procalcitonin was available from 1 and 13 patients in the two groups.

${ }^{\mathrm{b}} \operatorname{IgA}$, $\operatorname{IgM}$ and $\operatorname{IgG}$ were available from 9 and 11 patients in the two groups.

In group $\mathrm{NP}$ and $\mathrm{AP}$, the common symptoms were fever $(10,71.4 \% ; 14,70 \%)$ and cough $(13,92.6 \% ; 15,75 \%)$, merely $1(7.1 \%)$ and $3(15 \%)$ patients developed shortness of breath, as did the proportion of patients with lymphocytopenia. The incidence of severe cases in children was significantly lower than that in adults (Chen G et al. 2020; Chen N et al. 2020; Huang et al. 2020; Wang D et al. 2020; Wang XF et al. 2020). Lymphocytopenia was not common in children, it is true for another study (Wang D et al. 2020; Wang XF et al. 2020). In adult patients, lymphocytopenia is an important reference index for COVID-19 diagnosis and for the disease severity (Chen G et al. 2020; Chen N et al. 2020; Zhu et al. 2020). Thus, in children, the absence of lymphocytopenia is a remarkable difference. The average neutrophil count in group NP was lower than that in group AP $(P<0.05)$. It seemed to be negatively correlated with the higher level of viral nucleic acid in group NP. In both groups, $5(35.7 \%)$ and $9(45 \%)$ patients were co-infected with mycoplasma, $4(28.6 \%)$ and $2(10 \%)$ patients presented with respiratory syncytial virus (RSV) co-infection (Table 2).

In group NP, 6 (42.8\%) patients had ground-glass opacity, 10 (71.4\%) patients had local patchy shadowing, 6 (42.8\%) patients had bilateral patchy shadowing, and 11 (78.6\%) patients had right lung patchy shadowing on chest computed tomography (CT) scans (Supplementary Fig. S2). In group AP, there were 8 (40\%), 15 (75\%), 10 (50\%) and $13(65 \%)$ patients for each of four category imaging changes (Table 2). However, ground-glass opacities and bilateral lesions were observed in $60 \%$ and $75 \%-$ 

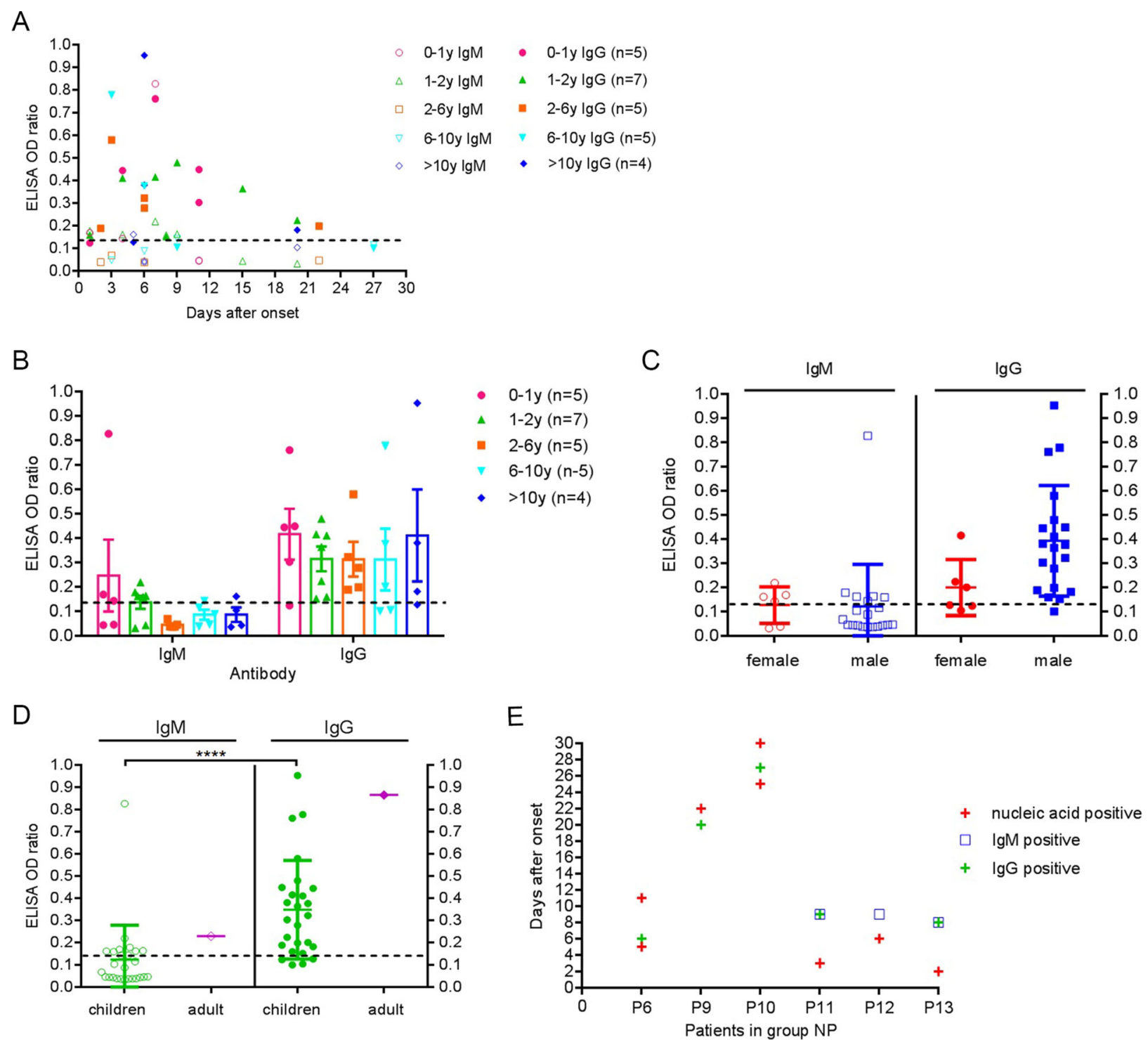

Fig. 2 SARS-CoV-2 antibody of 26 children patients in group NP and AP. A SARS-CoV-2 IgM and IgG of 26 children patients. B SARS-CoV-2 IgM and IgG levels at different age $(P>0.05)$. C SARS-CoV-2 IgM and IgG levels at different gender $(P>0.05)$.

D The level of SARS-CoV-2 IgM and IgG of 26 children and an adult. E SARS-CoV-2 nucleic acid and antibody detection of 6 patients in group NP. The dashed line indicates the cutoff value.

$100 \%$ adult patients, respectively (Chen G et al. 2020; Chen N et al. 2020; Huang et al. 2020; Wang D et al. 2020; Wang XF et al. 2020; Xia et al. 2020). Overall, lung inflammation in children was less severe than in adults.

Of the 26 patients with SARS-CoV-2 antibody positive in both groups, $3(11.5 \%), 16(61.5 \%)$, and $7(26.9 \%)$ patients were positive for only $\operatorname{IgM}$, only $\operatorname{IgG}$, and both $\operatorname{IgM}$ and $\operatorname{IgG}$, respectively (Table 1 ). $\operatorname{IgM}$ and $\operatorname{IgG}$ appeared at 1-9 days and 2-22 days after onset, respectively. In adults with COVID-19, the IgM and IgG were detected on 3-6 days and 10-18 days after onset (Guo et al. 2020). Thus, the specific antibody response to SARSCoV-2 in children appeared to be earlier than in adults. In

addition, the positive ratio of $\operatorname{IgG}$ in our study was $88.5 \%$, slightly higher than that of the adults (77.9\%), while IgM was $38.5 \%$, obviously lower than that of the adults (85.4\%) (Guo et al. 2020). The possible reason was that they took twice or three times blood samples per adult patient, whereas we took only one sample per child. For individuals, the specific antibody may not reach the detection threshold during the window period of serological conversion. Thus, repeated detection of SARS-CoV-2 antibodies at different time can further improve the positive rate of serological detection. Interestingly, a 2-month-old baby had high levels of $\operatorname{IgM}$ and $\mathrm{IgG}$ on 7 days after onset (Fig. 2A). The baby's mother was a confirmed case with 
COVID-19. So far, the investigators could not completely rule out the following two possibilities. First, the baby was infected by means of breast milk and (or) respiratory tract transmission. Second, the baby's antibodies were selfproduced and (or) the maternal antibody transfer through breastfeeding. Some small sample studies showed that the positive detection rate of SARS-COV-2 nucleic acid in breast milk was not high, and no infectious virus particles were isolated in breast milk with SARS-CoV-2 nucleic acid positive, but the composition of numerous breast milk proteins and metabolites changed significantly (Chambers et al. 2020; Groß et al. 2020; Zhao et al. 2020). The mother-to-child transmission of SARS-CoV-2 still needs a large-sample multi-center joint study to clarify.

No significant differences were detected in the mean level of IgM and IgG at different age $(P>0.05)$ (Fig. 2B), the same was true for SARS-CoV-2 antibody levels in different genders $(P>0.05)$ (Fig. $2 C)$. At present, there are no serological studies with age and gender as evaluation indicators of COVID-19. In addition, the specific IgM and $\mathrm{IgG}$ level in individual children were comparable to that of a convalescent adult with COVID-19 (Fig. 2D).

In group NP, two patients were positive for IgM and IgG at 8-9 days after onset. More than 20 days after onset, the other two patients were still positive for viral nucleic acids and $\mathrm{IgG}$ (Fig. 2E). Comprehensive analysis of SARS-CoV-2 antibody showed that the duration of the specific IgM positive was short, and the duration of the $\operatorname{IgG}$ positive was relatively long. Thus, specific IgG detection can also be used in epidemiology studies in large samples (Zhang et al. 2020).

Empirical antiviral therapy was administered to 13 (92.9\%) in group NP and $11(55.0 \%)$ patients in group AP, respectively $(P<0.05)$. As of 14 March 2020, all patients were recovered and discharged. From the results above, except for the neutrophil count, SARS-CoV-2 nucleic acid and specific IgG, and antiviral therapy, there were no significant differences between group NP and AP.

There were some limitations in the study. First, merely inpatients were enrolled, and outpatients who were asymptomatic or milder were not included. Second, SARSCoV-2 nucleic acid test and the specific antibody detection of synchronous breast milk were not performed. Third, merely a single blood sample from each patient was collected, and the investigators were unable to monitor the kinetic changes in the specific antibody class and titer.

In summary, COVID-19 in children had its own distinct epidemiological, clinical and serological characteristics, informing that protective isolation of infants, toddlers and school-aged children is critical, especially for boys in families. Lymphocytopenia should not be considered as a routine diagnostic criterion in children with COVID-19. Children with COVID-19 were more likely to be coinfected with mycoplasma. COVID-19 should be screened at the time of diagnosis in children with fever, cough and CT findings of lung involvement. The detection of SARSCoV-2 antibodies within 1-3 weeks after onset was of great value in diagnosing COVID-19, especially for SARSCoV-2 nucleic acid false negative. Mother-to-child transmission of infant cases with COVID-19 requires in-depth study.

Acknowledgements This study was supported by the Novel Pneumonia Emergency Science and Technology Project of Hubei Province (2020FCA004) and Youth Innovation Promotion Association of Chinese Academy of Sciences (2016302). We thank all patients and their families involved in the study. We also thank Hubei Provincial Center for Disease Control and Prevention.

\section{Compliance with Ethical Standards}

Conflict of interest The authors declare that they have no conflict of interest.

Human and Animal Rights This study was approved by the Institutional Ethics Board of Women and Children's Hospital of Hubei Province (No. 2020IECLW019). In view of the urgency to contain this outbreak, a written informed consent was exempted. Instead, an oral consent was obtained from the patient's family.

\section{References}

Badawi A, Ryoo SG (2016) Prevalence of comorbidities in the middle east respiratory syndrome coronavirus (MERS-CoV): a systematic review and meta-analysis. Int J Infect Dis 49:129-133

Chambers C, Krogstad P, Bertrand K, Contreras D, Tobin NH, Bode L, Aldrovandi G (2020) Evaluation for SARS-CoV-2 in breast milk from 18 infected women. JAMA 324:1347-1348

Chan JF-W, Yuan S, Kok K-H, To KK-W, Chu H, Yang J, Xing F, Liu J, Yip CC-Y, Poon RW-S, Tsoi H-W, Lo SK-F, Chan K-H, Poon VK-M, Chan W-M, Ip JD, Cai J-P, Cheng VC-C, Chen H, Hui CK-M, Yuen K-Y (2020) A familial cluster of pneumonia associated with the 2019 novel coronavirus indicating person-toperson transmission: A study of a family cluster. Lancet 395:514-523

Channappanavar R, Fett C, Mack M, Ten Eyck PP, Meyerholz DK, Perlman S (2017) Sex-based differences in susceptibility to severe acute respiratory syndrome coronavirus infection. J Immunol 198:4046-4053

Chen G, Wu D, Guo W, Cao Y, Huang D, Wang H, Wang T, Zhang $\mathrm{X}$, Chen H, Yu H, Zhang X, Zhang M, Wu S, Song J, Chen T, Han M, Li S, Luo X, Zhao J, Ning Q (2020) Clinical and immunological features of severe and moderate coronavirus disease 2019. J Clin Invest 130:2620-2629

Chen N, Zhou M, Dong X, Qu J, Gong F, Han Y, Qiu Y, Wang J, Liu Y, Wei Y, Xia Ja YuT, Zhang X, Zhang L (2020) Epidemiological and clinical characteristics of 99 cases of 2019 novel coronavirus pneumonia in Wuhan, China: a descriptive study. Lancet 395:507-513

Cui Y, Tian M, Huang D, Wang X, Huang Y, Fan L, Wang L, Chen Y, Liu W, Zhang K, Wu Y, Yang Z, Tao J, Feng J, Liu K, Ye X, Wang R, Zhang X, Zha Y (2020) A 55-day-old female infant infected with 2019 novel coronavirus disease: presenting with 
pneumonia, liver injury, and heart damage. J Infect Dis 221:1775-1781

Groß R, Conzelmann C, Müller JA, Stenger S, Steinhart K, Kirchhoff F, Münch J (2020) Detection of SARS-CoV-2 in human breastmilk. Lancet 395:1757-1758

Guo L, Ren L, Yang S, Xiao M, Chang D, Yang F, Dela Cruz CS, Wang Y, Wu C, Xiao Y, Zhang L, Han L, Dang S, Xu Y, Yang QW, Xu SY, Zhu HD, Xu YC, Jin Q, Sharma L, Wang L, Wang J (2020) Profiling early humoral response to diagnose novel coronavirus disease (COVID-19). Clin Infect Dis 71:778-785

Guo L, Wei D, Zhang X, Wu Y, Li Q, Zhou M, Qu J (2019) Clinical features predicting mortality risk in patients with viral pneumonia: The MuLBSTA score. Front Microbiol 10:2752

Huang C, Wang Y, Li X, Ren L, Zhao J, Hu Y, Zhang L, Fan G, Xu J, Gu X, Cheng Z, Yu T, Xia J, Wei Y, Wu W, Xie X, Yin W, Li H, Liu M, Xiao Y, Gao H, Guo L, Xie J, Wang G, Jiang R, Gao Z, Jin Q, Wang J, Cao B (2020) Clinical features of patients infected with 2019 novel coronavirus in Wuhan, China. Lancet 395:497-506

Li Q, Guan X, Wu P, Wang X, Zhou L, Tong Y, Ren R, Leung KSM, Lau EHY, Wong JY, Xing X, Xiang N, Wu Y, Li C, Chen Q, Li D, Liu T, Zhao J, Liu M, Tu W, Chen C, Jin L, Yang R, Wang Q, Zhou S, Wang R, Liu H, Luo Y, Liu Y, Shao G, Li H, Tao Z, Yang Y, Deng Z, Liu B, Ma Z, Zhang Y, Shi G, Lam TTY, Wu JT, Gao GF, Cowling BJ, Yang B, Leung GM, Feng Z (2020) Early transmission dynamics in Wuhan, China, of novel coronavirus-infected pneumonia. N Engl J Med 382:1199-1207

Lu X, Zhang L, Du H, Zhang J, Li YY, Qu J, Zhang W, Wang Y, Bao S, Li Y, Wu C, Liu H, Liu D, Shao J, Peng X, Yang Y, Liu Z, Xiang Y, Zhang F, Silva RM, Pinkerton KE, Shen K, Xiao H, Xu S, Wong GWK (2020) SARS-CoV-2 infection in children. N Engl J Med 382:1663-1665

Su L, Ma X, Yu H, Zhang Z, Bian P, Han Y, Sun J, Liu Y, Yang C, Geng J, Zhang Z, Gai Z (2020) The different clinical characteristics of corona virus disease cases between children and their families in China - the character of children with COVID-19. Emerg Microbes Infect 9:707-713

Wang D, Hu B, Hu C, Zhu F, Liu X, Zhang J, Wang B, Xiang H, Cheng Z, Xiong Y, Zhao Y, Li Y, Wang X, Peng Z (2020) Clinical characteristics of 138 hospitalized patients with 2019 novel coronavirus-infected pneumonia in Wuhan, China. JAMA 323:1061-1069

Wang XF, Yuan J, Zheng YJ, Chen J, Bao YM, Wang YR, Wang LF, Li H, Zeng JX, Zhang YH, Liu YX, Liu L (2020) Retracted: Clinical and epidemiological characteristics of 34 children with 2019 novel coronavirus infection in Shenzhen. Zhonghua Er Ke Za Zhi 58:E008 (In Chinese)

Xia W, Shao J, Guo Y, Peng X, Li Z, Hu D (2020) Clinical and CT features in pediatric patients with COVID-19 infection: Different points from adults. Pediatr Pulmonol 55:1169-1174

Zhang W, Du RH, Li B, Zheng XS, Yang XL, Hu B, Wang YY, Xiao GF, Yan B, Shi ZL, Zhou P (2020) Molecular and serological investigation of 2019-nCoV infected patients: implication of multiple shedding routes. Emerg Microbes Infect 9:386-389

Zhao Y, Shang Y, Ren Y, Bie Y, Qiu Y, Yuan Y, Zhao Y, Zou L, Lin SH, Zhou X (2020) Omics study reveals abnormal alterations of breastmilk proteins and metabolites in puerperant women with COVID-19. Signal Transduct Target Ther 5:247

Zhou P, Yang XL, Wang XG, Hu B, Zhang L, Zhang W, Si HR, Zhu Y, Li B, Huang CL, Chen HD, Chen J, Luo Y, Guo H, Jiang RD, Liu MQ, Chen Y, Shen XR, Wang X, Zheng XS, Zhao K, Chen QJ, Deng F, Liu LL, Yan B, Zhan FX, Wang YY, Xiao GF, Shi ZL (2020) A pneumonia outbreak associated with a new coronavirus of probable bat origin. Nature 579:270-273

Zhu J, Kim J, Xiao X, Wang Y, Luo D, Chen R, Xu L, Zhang H, Xiao G, Zhan X, Wang T, Xie Y (2020) Profiling the immune vulnerability landscape of the 2019 Novel Coronavirus. bioRxiv https://doi.org/10.1101/2020.02.08.939553:2020.2002.2008. 939553 